Nevşehir Bilim ve Teknoloji Dergisi (2019), 8(IMSMATEC Özel Sayı) 54-62

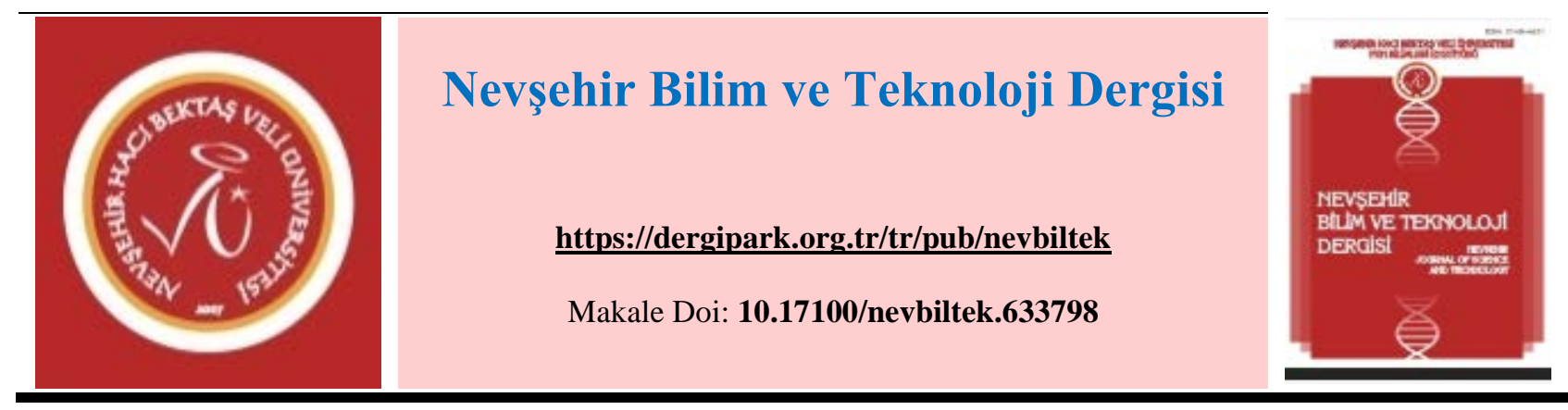

\title{
Farklı Presleme Basınçları İle Üretilen Toz Metal Çeliklerin Aşınma Davranışlarının Belirlenmesi
}

\author{
İjlal ŞiMŞEK ${ }^{1}$, Dursun ÖZYÜREK ${ }^{2}$, Doğan ŞİMŞEK ${ }^{3}$ \\ ${ }^{1}$ Karabük Üniversitesi, TOBB Teknik Bilimler Meslek Yüksekokulu, Makine ve Metal Teknolojileri Bölümü, Karabük \\ ORCID ID: 0000-0001-6542-8567
}

${ }^{2}$ Karabük Üniversitesi, Teknoloji Fakültesi, Imalat Mühendisliği Bölümü, Karabük ORCID ID: 0000-0002-8326-9982

${ }^{3}$ Milli Savunma Üniversitesi, Kara Astsubay Meslek Yüksekokulu, Otomotiv Teknolojileri Bölümü, Karabük ORCID ID: 0000-0001-8339-9704

Öz

Yapılan bu çalışmada, toz metalürjisi ile farklı presleme basınçları ile üretilen Fe-\%3Si-\%2Ni-\%0,35Gr (grafit) bileşimine sahip alaşımlarının sabit yük altında aşınma davranışları incelenmiştir. Türbüla tipi değirmende $20 \mathrm{dk}$ karıştırılan tozlar üç farklı (300 MPa, $500 \mathrm{MPa}$ ve $700 \mathrm{MPa})$ presleme basıncı kullanılarak preslenmiş ve ham numuneler üretilmiştir. Üretilen ham numuneler argon gazı atmosferinde, $1200{ }^{\circ} \mathrm{C}$ sıcaklıkta 30 dakika sinterlenmiştir. Üretilen numuneler, mikro yapı incelemeleri, sertlik ve yoğunluk ölçümleri ile karakterize edilmiştir. Sinterleme öncesi ve sonrası yoğunluk ölçümleri yapılmış ve gözeneklilik oranı belirlenmiştir. Aşınma testleri standart pin on disk aşınma tipi test cihazında $50 \mathrm{~N}$ yük altında 3 farklı (1000 m, $2000 \mathrm{~m}$ ve $3000 \mathrm{~m})$ kayma mesafesi kullanılmıştır. Elde edilen sonuçlarda artan presleme basıncı ile yoğunluğun arttı̆̆ı ve beraberinde gözenek oranının azaldığı görülmüştür. Aşınma testleri sonucunda en yüksek ağırlık kaybının 500 MPa basınçla preslenen alaşımda elde edilirken, en düşük ağırlık kaybının $700 \mathrm{MPa}$ basınçla preslenen alaşımda elde edilmiştir.

Anahtar Kelimeler: Düşük karbonlu çelik, presleme, aşınma, gözeneklilik.

\section{Determination of Wear Behavior of Powder Metal Steels Produced by Different Pressing Pressures}

\begin{abstract}
In this study, was investigated the wear behavior of alloys with $\mathrm{Fe}-3 \% \mathrm{Si}-2 \% \mathrm{Ni}-\% 0.35 \mathrm{Gr}$ composition produced by different pressing pressures with powder metallurgy. The powders were mixed for 20 minutes in the turbine type mill, green compacts were produced that pressed using three different pressing pressures (300 MPa, $500 \mathrm{MPa}$ and $700 \mathrm{MPa}$ ). The produced green compacts were sintered in argon gas atmosphere, at $1200{ }^{\circ} \mathrm{C}$ temperature for $30 \mathrm{~min}$. The produced samples were characterized by microstructure analysis, hardness and density measurements. The density measurements were made before and after sintering and the porosity rate was determined. The wear tests were made on the standard pin-on-disc wear machine, at 3 different (1000 m, $2000 \mathrm{~m}$ and $3000 \mathrm{~m}$ ) sliding distances and under $50 \mathrm{~N}$ load. In the results, it was observed that the porosity decreases and the density increased with the increasing pressing pressure. As a result of the wear tests, the highest weight loss was obtained in the pressed alloy with $500 \mathrm{MPa}$ pressure, while the lowest weight loss was obtained in the pressed alloy with $700 \mathrm{MPa}$ pressure.
\end{abstract}

Keywords: Low alloys steels, pressing, wear, porosity. 
Nevşehir Bilim ve Teknoloji Dergisi (2019), 8(IMSMATEC Özel Sayı) 54-62

\section{Giriş}

Nikel (Ni) ve Mangan (Mn) ilaveli toz metal (TM) çeliklerinin mikro yapılarında genel olarak görülen Nizengin ferrit ve martensit gibi fazlar, bu çeliklerinin mekanik özelliklerinin geliştirilmesine katkı sağlamaktadır. Östenit stabilizatörü olan Ni ve Mn alaşım elemanları olarak sertleşebilirliği önemli ölçüde artırmaktadır [1 ve 2]. Bununla birlikte, silisyumun ( $\mathrm{Si}$ ) iyi bir ferrit stabilizatörü olduğu ve ferritte katı bir çözelti kuvvetlendirici etkiye sahip olduğu bilinmektedir. Silisyum elementi düşük alaşımlı çeliklerde, iyi güçlendirme ve Ni ve Mo'ya göre ucuz olmasından dolayı yaygın olarak kullanılmaktadır [3]. Ni ilave edilen TM çeliklerin mikro yapılarındaki zengin Ni'ce zengin ferrit ve martenzit gibi fazlar TM çeliklerin mekanik özelliklerine katkı sağlamaktadır [4].

TM çeliklerin aşınma davranışlarını, mikro yapı, sertlik, kimyasal bileşim, yoğunluk ve gözeneklilik oranı gibi özellikler etkilemektedir [5]. Genellikle TM çeliklerin aşınma direncinin artırılması için yüksek yoğunluk istenmektedir. Aşınma özelliklerinin iyileştirilmesinde en yaygın yöntem alaşım elementleri kullanmaktadır. Tekeli vd. [4], Fe-\%3Si-\%2Ni ve Fe-\%3Si-\%2Mn alaşımlarına farklı miktarlarda grafit miktarının alaşımına davranışları üzerine etkisini incelmişlerdir. Mn içeren alaşımlarda yüzeyde meydana gelen kırılmalar nedeniyle aşınma direncinin azaldığını, Ni ilave edilen alaşımlarda ise daha iyi aşınma direnci olduğunu ve aşınmanın ise yüzeyde plastik deformasyon ile gerçekleştiğini belirtmişlerdir. Bunun yanı sıra Dhanasekaran ve Gnanamoorthy [6] matris içerisinde artan sert ve kırılgan fazların varlığının alaşımın tokluğunu azalttığını ve bu nedenle aşınma direncinin de zayıfladığını belirtmişlerdir. TM çeliklerin gözeneklilik oranı aşınma davranışlarını önemli ölçüde etkilemektedir. Simchi ve Danninger [5], yaptıkları bir çalışmada farklı gözenek oranına sahip TM çeliklerin aşınma davranışlarını incelemiş ve TM çeliklerin aşınma mekanizmalarının dövme çeliklerle benzer olduğunu belirtmişlerdir. Bununla birlikte yüzeydeki gözeneklerin aşınma oranında önemli bir etkisinin olduğunu da belirtmişlerdir.

Yapılan bu çalışmada, TM yöntemi ile üretilen FeSiNiGr alaşımı farklı presleme basıncı ile üretilmiştir. Üretilen TM çelik alaşımlarında, farklı presleme basınçlarının mikro yapı, yoğunluk, sertlik ve sabit yük altında aşınma davranışına etkisinin belirlenmesi hedeflenmiştir.

\section{Materyal ve Metot}

Yapılan bu çalı̧̧mada, ortalama toz boyutu $40 \mu \mathrm{m} \% 99$ saflıkta demir (Fe), ortalama 400 mesh \%99,8 saflıkta Nikel (Ni), 325 mesh \%99,5 saflıkta silisyum (Si) ve ortalama toz boyutunun $41 \mu \mathrm{m} \% 99$ saflıkta grafit kullanılmıştır. Üretilen TM çeliklerin kimyasal bileşimi Tablo 1'de verilmiştir.

Tablo 1. Üretilen TM çeliklerin kimyasal bileşimi

\begin{tabular}{ccccc}
\hline Element & $\mathbf{S i}$ & $\mathbf{N i}$ & $\begin{array}{c}\mathbf{G r} \\
\text { (grafit) }\end{array}$ & $\mathbf{F e}$ \\
\hline \% ağ. & 3 & 2 & 0,35 & Kalan \\
\hline
\end{tabular}

Çizelge 1'de verilen kimyasal bileşime göre hazırlanan tozlar, türbüla tipi toz karıştırma cihazında 4/1 karıştırma kabı/toz oranı kullanılarak 20 dakika süre ile mekanik karıştırılmıştır. Karıştırma işlemi ile hazırlanan tozlar paslanmaz çelik kalıp ile 3 farklı presleme basınçlarında (300 MPa, 500 MPa ve $700 \mathrm{MPa}$ ) preslenmiş ve ham numuneler üretilmiştir. Üretilen ham numuneler atmosfer kontrollü firında argon gazı atmosferinde $5{ }^{\circ} \mathrm{C} / \mathrm{dk} 1$ sıtma hızı kullanılarak $1200{ }^{\circ} \mathrm{C}$ sıcaklıkta 30 dakika süre ile sinterlenmiş ve $4{ }^{\circ} \mathrm{C} / \mathrm{dk}$ soğutma hızı kullanılarak firın ortamında oda sıcaklığına kadar soğutulmuştur. Üretilen numunelerde sinterleme öncesi ve sonrası yoğunluk ölçümleri ve sinterleme sonrası sertlik ölçümleri ile karakterize edilmiştir. Üretilen numuneler standart metalografik işlemler ile hazırlanmış ve \%3'lük nital dağlayıcı ile 10-15 saniye dağlanmıştır. Dağlanan numuneler mikro yapı çalışmalarında Jeol JSM 6060 
Nevşehir Bilim ve Teknoloji Dergisi (2019), 8(IMSMATEC Özel Sayı) 54-62

marka Taramalı Elektron Mikroskobu (SEM) kullanılmıştır. Üretilen numunelerin sertlik ölçümleri Shimadzu HMV marka test cihazında HV0,2 olarak ölçülmüştür. Sertlik ölçümleri her numunede 5 ölçüm noktasından alınmış ve ortalama değer hesaplanmıştır. Aşınma testleri standart pin on disk aşınma test cihazında $50 \mathrm{~N}$ yük altında 3 faklı (1000 m, 2000 m ve $3000 \mathrm{~m}$ ) kayma mesafesi kullanılmıştır. Aşınma testleri sonrasında ağırlık kaybı aşınma oranı ve sürtünme katsayıları ile incelenmiş̧ir. Aşınma oranı Eşitlik 1'de verilen bağıntı ile hesaplanıştır.

$$
\mathrm{Wa}=\Delta \mathrm{m} /(\text { M.s.p) }
$$

Burada Wa aşınma oranı, $\Delta \mathrm{m}$ aşınma testi sonrasında elde edilen ağırlık kaybı (g), M testlerde kullanılan yük $(\mathrm{N})$, s kayma mesafesi $(\mathrm{m})$ ve $\rho$ aşınma numunesinin yoğunluğudur $\left(\mathrm{gr} / \mathrm{cm}^{3}\right)$. Aşınma testi sonrası aşınmış yüzey SEM görüntüleri incelenerek, aktif aşınma mekanizmaları belirlenmeye çalışılmıştır.

\section{Sonuçlar ve Tartışma}

Farklı presleme basınçlarında üretilen TM çeliklerin mikro yapı SEM görüntüleri Şekil 1'de verilmiştir.
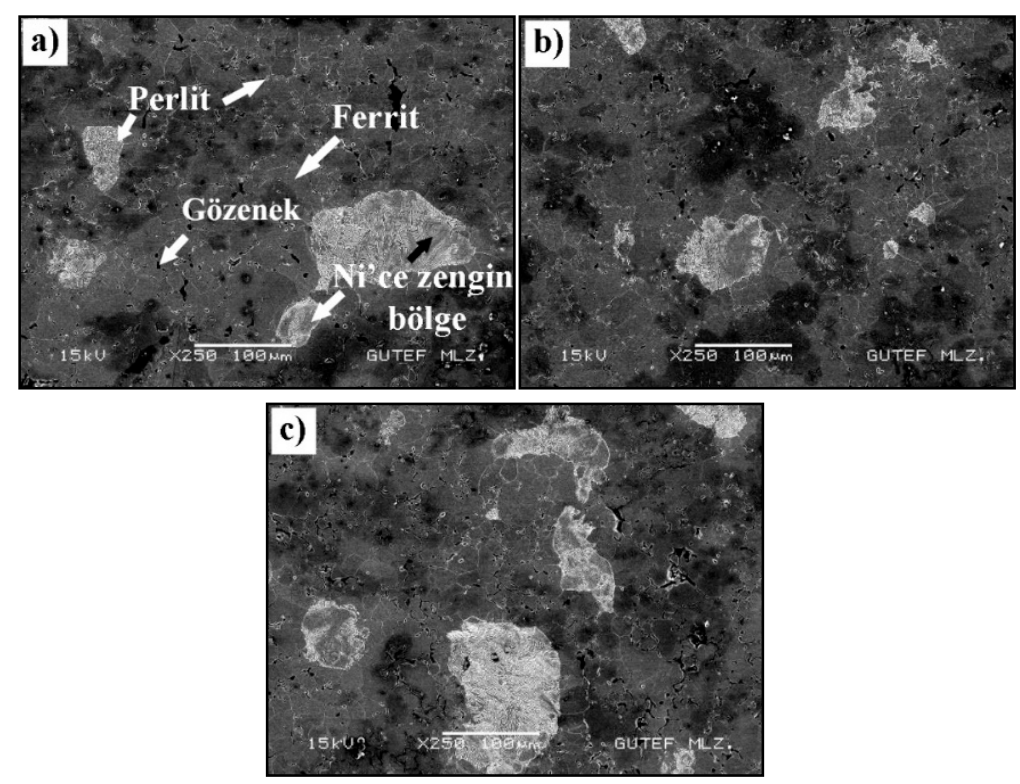

Şekil 1. Farklı presleme basınçlarında üretilen TM çeliklerin mikro yapı SEM görüntüleri a) $300 \mathrm{MPa}$, b) $500 \mathrm{MPa}$ ve C) $700 \mathrm{MPa}$

Şekil 1'de verilen farklı presleme basınçlarında üretilen TM çeliklerin mikro yapı SEM görüntüleri incelendiğinde, tüm presleme basınçlarında yapının ferrit ve perlit fazlarından oluştuğu anlaşılmaktadır. Tüm presleme basınçlarında geniş perlit yapılı alanlar ile birlikte özellikle tane sınırlarında perlitik dönüşümlerin oluştuğu görülmektedir. Bununla birlikte artan presleme basıncıyla bu alanların genişlediği görülmektedir. Bu durum toz karıştırma esnasında ilave edilen grafit (C) tozlarının demir (Fe) tozları yüzeyine sıvanmasından kaynaklandığı düşünülmektedir. Ayrıca sinterleme esnasında tane sınırlarında C çözünerek perlit dönüşümüne neden olmaktadır. Mikro yapıda geniş perlitik alanlar içerisinde farklı alanların olduğu görülmektedir. Bu alanlar Ni'ce zengin bölgeler olduğu düşünülmektedir. Daha önce Tekeli vd. [4] tarafından yapılan benzer bir çalışmada perlitik yapı içerisinde çözünmemiş Ni'ce zengin bölgelerin olduğunu, bunun nedeninin ise Ni difüzyon hızının düşük olmasından ve $1100{ }^{\circ} \mathrm{C}$ $1250{ }^{\circ} \mathrm{C}$ sıcaklıklarda Ni’nin sınırlı çözünmesinden kaynaklandığı belirtilmektedir. Ayrıca mikro yapıda artan presleme basıncı ile gözenek oranında azalmanın olduğu net bir şekilde anlaşılmaktadır. Farklı presleme basınçları ile üretilen TM çeliklerin yoğunluk değerleri ve gözeneklilik oranları Şekil 2'de verilmiştir. 


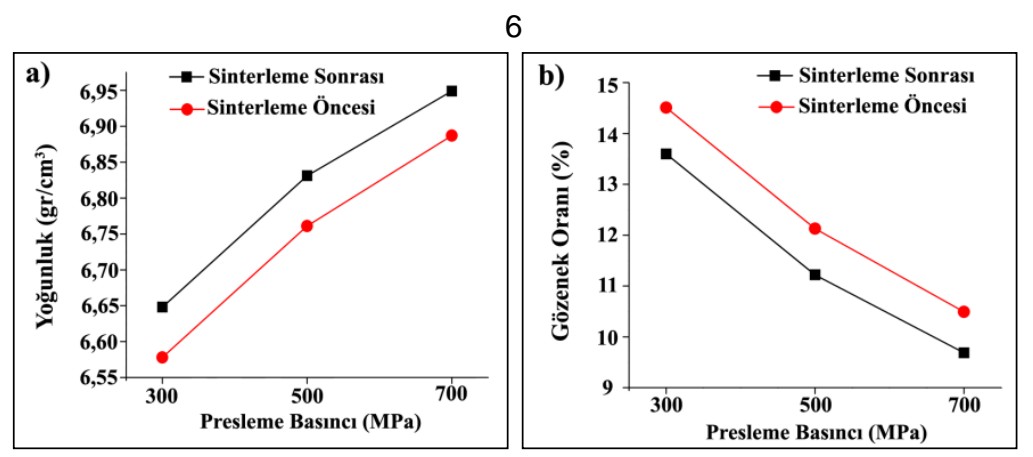

Şekil 2. Farklı presleme basınçlarında üretilen TM çeliklerin a) yoğunluk ve b) gözeneklilik oranı

Şekil 2.a'da verilen farklı presleme basınçlarında üretilen TM çeliklerin yoğunluk değiş̧imi incelendiğinde, artan presleme basıncı ile hem sinterleme öncesi hem de sinterleme sonrası yoğunluklarının artığı görülmektedir. Sinterleme sonrası en yüksek yoğunluk $700 \mathrm{MPa}$ basınç altında preslenen numunede $6,949 \mathrm{gr} / \mathrm{cm}^{3}$ olarak ede edilirken en düşük yoğunluk $300 \mathrm{MPa}$ basınçla sinterlenen numunede $6,648 \mathrm{gr} / \mathrm{cm}^{3}$ olarak elde edilmiştir. Benzer şekilde sinterleme öncesinde de en yüksek yoğunluk $700 \mathrm{MPa}$ basınçla sinterlenen numunede $6,887 \mathrm{gr} / \mathrm{cm}^{3}$ olarak elde edilirken en düşük yoğunluk $300 \mathrm{MPa}$ basınçla sinterlenen numunede $6,578 \mathrm{gr} / \mathrm{cm}^{3}$ olarak elde edilmiştir. Elde edilen sonuçlar beklenen bir durumdur. Artan sıkıştırma basıncı ile daha kompakt hale gelen numunelerin yapısında küçülen gözenekler sinterleme esnasında tanelerin birbiri arasındaki daha iyi difüzyonu ile kapanmaktadır. Bu durum Şekil 2.b’de verilen gözenek oranı sonuçlarından açıkça anlaşılmaktadır.

Yine Şekil 2.b'de verilen gözenek oranı sonuçları incelendiğinde en yüksek gözeneklilik oranının $300 \mathrm{MPa}$ basınçta preslenen ve sinterlenmeyen numunede $\% 14,5$ olarak elde edilirken sinterlenen aynı numunede ise gözenek oranı ise \% 13,5 olarak elde edilmiştir. Benzer şekilde en düşük gözeneklilik oranı $700 \mathrm{MPa}$ basınç altında sinterlenen numunede elde edilmiştir. Artan presleme basıncı ile gözeneklilik oranının azaldığı anlaşılmaktadır. Ancak yine gözeneklilik oranı sonuçlarından anlaşılacağı gibi 300 MPa basınçla preslenen numunede sinterleme sonrası, sinterleme öncesine göre, gözeneklilik oranında yaklaşık \%1'lik bir azalma olurken, presleme basıncı $700 \mathrm{MPa}$ 'ya çıması ile yaklaşı \% 0,8'lik bir azalma olduğu görülmektedir. Bu durum sinterleme esnasında gözeneklerde kalan gazın yapıdan ayrılamamasından kaynaklandığı düşünülmektedir. Daha önce yapılan bazı çalışmalarda presleme basıncının artması ile gözeneklilik oranının belirli bir orana kadar azaldığı ve buna bağlı olarak yoğunluğun arttığı, ancak daha fazla artan presleme basıncı ile yapıdaki gözeneklerin yoğunlaşmaya karşı direncinin arttığı belirtilmiştir [7 ve 8]. Farklı presleme basınçları ile üretilen TM çeliklerin sertlik değerleri Şekil 3'de verilmiştir.

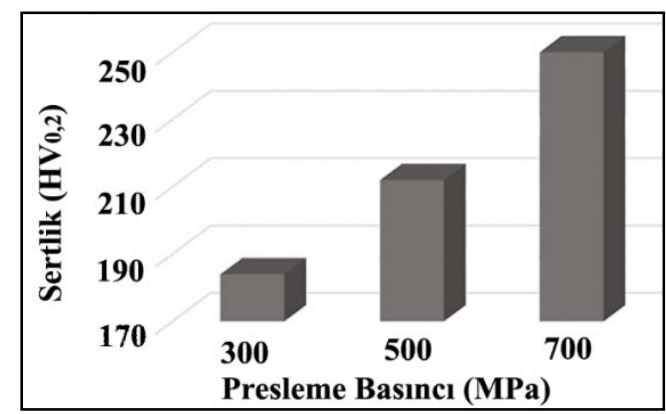

Şekil 3. Farklı presleme basınçlarında üretilen TM çeliklerin sertlik sonucu

Şekil 3'te verilen farklı presleme basınçlarında üretilen TM çeliklerin sertlik sonuçları incelendiğinde artan presleme basıncı ile sertlik değerlerinin arttığı görülmektedir. En yüksek sertlik değeri 700 MPa basınçla preslenen TM 
Nevşehir Bilim ve Teknoloji Dergisi (2019), 8(IMSMATEC Özel Sayı) 54-62

çelikte 254 HV elde edilirken, en düşük sertlik 300 MPa basınçla preslenen TM çelikte elde edilmiştir. Presleme basıncının artması ile sertliğin artması sıkıştırma esnasında meydana gelen deformasyon etkisi ile birlikte yapıdaki gözenek oranının azalmasından kaynaklandığı düşünülmektedir. Toz metalürjisi yöntemi ile üretilen parçaların mekanik özellikleri gözenek oranı ile ilişkilidir. Yapıda oluşan gözenekler gerilimin yoğunlaştığı merkezler olarak davranırken dislokasyonların ilerlemesine de katkı sağlamaktadır [8]. Bununla birlikte presleme basıncının artması ile yapıda bölgesel olarak artan perlitik yapının sertliğin artmasının diğer bir nedenidir. Farklı presleme basınçları ile üretilen TM çeliklerin sabit yük altında ağırlık kaybı ve aşınma oranı Şekil 4'de verilmiştir.

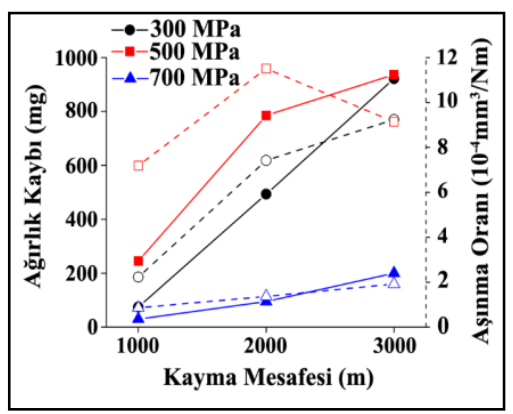

Şekil 4. Farklı presleme basınçlarında üretilen TM çeliklerin ağırlık kaybı ve aşınma oranı sonuçları

Şekil 4'te verilen farklı presleme basınçlarında üretilen TM çeliklerin ağırlık kaybı sonuçları incelendiğinde, bütün basınçlarda artan kayma mesafesi ile ağırlık kaybının arttı̆̆ı anlaşılmaktadır. Ayrıca $700 \mathrm{MPa}$ basınçla üretilen TM çelik numunede en düşük ağılık kaybının olduğu görülmektedir. Şekil 3’te verilen sertlik sonuçları bu durumu desteklemektedir. Ancak 300 MPa ve 500 MPa basınçla üretilen TM çeliklerin ağırlık kaybı sonuçları sertlik sonuçları ile uyum sağlamamaktadır. Ağırlık kaybı sonuçlarından beklenen $500 \mathrm{MPa}$ basınç altında üretilen TM çelik numunede, $300 \mathrm{MPa}$ üretilen TM çelik numuneden daha düşük olması beklenmektedir. Bu durum yapıdaki gözenek oranından kaynaklandığı düşünülmektedir. Tribolojik sistemden uzaklaşamayan aşınma parçacıklarının, hem sertliğin düşük olmasından hem de gözeneklerin fazla olmasından dolayı tekrardan malzemeye yapışmasından kaynaklandığı düşünülmektedir. Dubrujeaured vd. [9], yaptıkları bir çalışmada gözenek boyutunun sinterlenmiş çeliklerin aşınma performanslarında önemli bir parametre olduğunu belirtmişlerdir. Yine Şekil 4'te verilen aşınma oranı sonuçları bu durumu desteklemektedir. Bütün numunelerde aşınma testi başlarında artan aşınma oranları, $500 \mathrm{MPa}$ basınçta üretilen TM çelik numunde $2000 \mathrm{~m}$ kayma mesafesinden sonra azaldığı görülmektedir. Benzer şekilde $300 \mathrm{MPa}$ basınçla üretilen numunede ise $2000 \mathrm{~m}$ kayma mesafesinden sonra daha yatay bir konumda olduğu görülmektedir. Bu durum daha önce yapılan bir çalışmada gözenek oranı daha yüksek olan sinterlenmiş demirde aşınma oranının düşük olduğunu, bunun nedeninin ise aşınma esnasında oluşan metalik atıkları daha kolay tutan yüzeydeki mevcut büyük gözeneklerin olduğunu belirtilmektedir [5]. Farklı presleme basınçları ile üretilen TM çeliklerin sabit yük altında sürtünme katsayıları Şekil 5’te verilmiştir. 
Nevşehir Bilim ve Teknoloji Dergisi (2019), 8(IMSMATEC Özel Sayı) 54-62

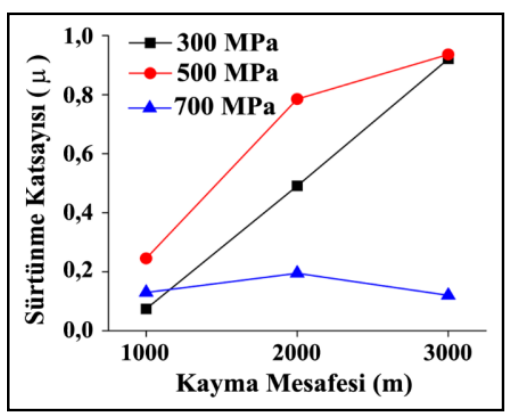

Şekil 5. Farklı presleme basınçlarında üretilen TM çeliklerin sürtünme katsayıları

Şekil 5'te verilen farklı presleme basınçlarında üretilen TM çelik numunelerin sürtünme katsayıları incelendiğinde, bütün numunelerde genel olarak, artan kayma mesafesi ile artma yönünde olduğu görülürken, $700 \mathrm{MPa}$ basınçla üretilen TM çelik numunede ise $2000 \mathrm{~m}$ kayma mesafesinden sonra sürtünme katsayısında azalma olduğu görülmektedir. Bu durum $700 \mathrm{MPa}$ basınçla üretilen TM çelik numunenin hem sertliğinin yüksek olması hem de gözenek oranının düşük olmasından kaynaklanmaktadır. Aşınma testleri esnasında daha sert parçaların sürtünme katsayısının düşük olması kabul gören bir metalürjik kuraldır. $300 \mathrm{MPa}$ ve $500 \mathrm{MPa}$ basınçla üretile TM çelik numunelerde sürtünme katsayısında sürekli bir artış olmaktadır. Ancak $2000 \mathrm{~m}$ kayma mesafesinden sonra $500 \mathrm{MPa}$ basınçla üretilen TM çelikte sürtünme katsayısının daha düzlemsel bir hale geldiği görülmektedir. Bu durum aşınma esnasında plastik deformasyona uğrayarak kopan sert aşınma parçacıklarının yüzeye tekrardan yapışarak sürtünme temas alanının azaltmasından kaynaklanmaktadır. Sürtünme katsayılarından genel olarak sertlik sonuçları ile uyumlu olması beklenmektedir. Elde edilen sonuçlar bu durumu desteklememektedir. Daha önce yapılan bir çalışmada da benzer sonuçlar elde edilmiştir. Simchi ve Danninger [5], sinterlenmiş çelliklerde gözenek oranın artması ile sürtünme katsayısının azaldığını belirtmişlerdir. Farklı presleme basınçları ile üretilen TM çeliklerin sabit yük altında aşınma yüzeyi SEM görüntüleri Şekil 6'da verilmiştir.
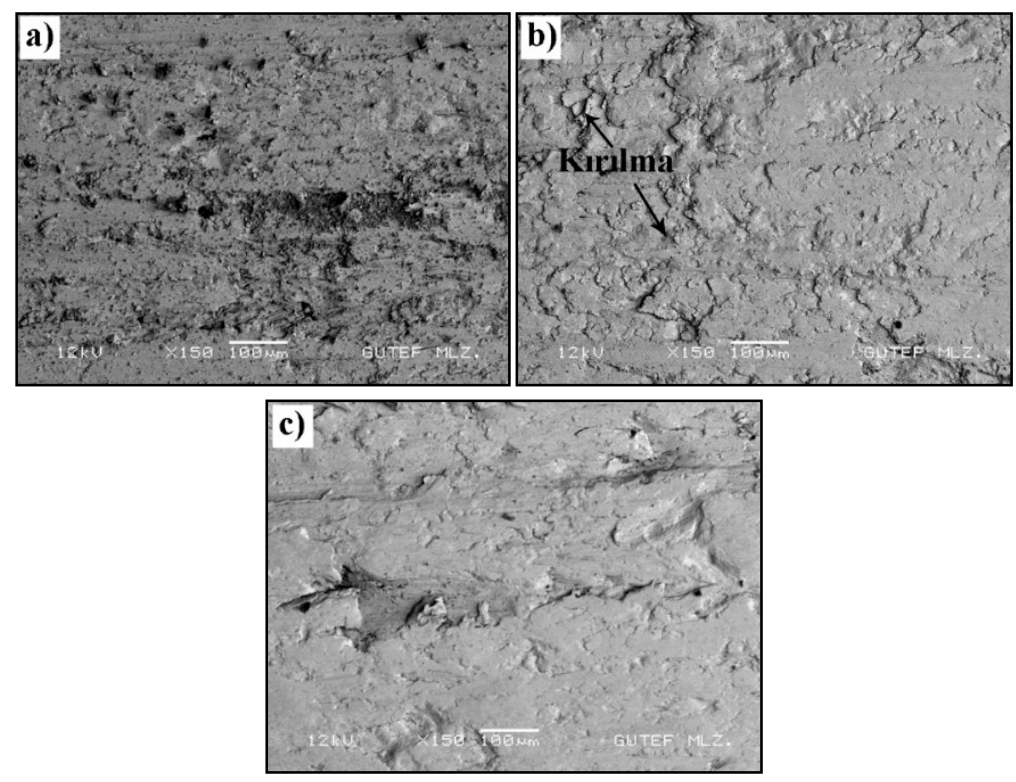

Şekil 6. Farklı presleme basınçlarında üretilen TM çeliklerin aşınma yüzeyi SEM görüntüleri

Şekil 6'da farklı presleme basınçlarında üretilen TM çelik numunelerin aşınma yüzey SEM görüntüleri incelendiğinde, kayma yönü boyunca deformasyon izleri açık bir şekilde görülmektedir. Ayrıca en yüksek ağırlık kaybının elde edildiği (500 MPa) numune aşınma yüzeyinde yüzeyde meydana gelen hasarın diğer numunelere göre 
Nevşehir Bilim ve Teknoloji Dergisi (2019), 8(IMSMATEC Özel Sayı) 54-62

daha belirgin olduğu anlaşılmaktadır. Bu durum hem Şekil 4. Ağırlık kaybı aşınma oranı sonuçları hem de Şekil 5. Sürtünme katsayısı sonuçlarını desteklemektedir. Ayrıca artan sertlikle birlikte daha pürüzsüz aşınma yüzeyine sahip olana 700 MPa basınçla üretilen TM çelik numunede ise aşınma yönü boyunca daha ince plastik deformasyon izleri görülmektedir. Tekeli vd. [4] yaptıkları benzer bir çalışmada Ni ilave edilmiş TM çeliklerde katmanlı aşınma mekanizmasının daha baskın olduğunu bunun nedeninin ise düşük miktarda perlit ve düşük sertlikten kaynaklandığını belirtmişlerdir. Bunula birlikte sertliği ve perlit miktarı artan Ni ilaveli TM çeliklerde ise daha düşük aşınma oranın sahip pürüzsüz aşınma yüzeyinin oluştuğunu belirtmişlerdir. Şekil 6.a'da ise azda olsa katmanlı aşınma mekanizmasının olduğu anlaşılmaktadır. Bu durum daha önce yapılan bir çalışmada yüzeyde ve yüzeyin hemen altında bulunan gözeneklerin gerilme dağılımı ve metal deformasyonunda farklılık gösterdiğginden numunelerde oluşan deformasyonlarında farklılık gösterebileceğini belirtmişlerdir [4].

\section{Sonuçlar}

Farklı presleme basınçları ile üretilen Fe3Si2Ni0,35Gr alaşımlı TM çelik malzemelerin sabit yük altındaki aşınma davranışının incelendiği bu çalışmada elde edilen sonuçlar aşağıda belirtilmiştir.

- Yapılan çalışmada sinterleme sonrası yapıda perlit dönüşümünün olduğu görülmüştür. Perlit dönüşümünün bölgesel olmakla birlikte tane sınırlarında olduğu görülmüştür. Artan presleme basıncı ile daha geniş bölgesel perlit dönüşümü olduğu görülmüş̧ür.

- Artan presleme basınc1 ile hem sinterleme öncesi hem de sinterleme sonrası yoğunlukların arttığı belirlenmiştir. Ayrıca artan presleme basıncı ile gözenek oranının azaldığı belirlenmiştir.

- Artan presleme basıncı ile TM çelik alaşımlarının sertlikleri arttığı belirlenmiştir. En yüksek sertlik $700 \mathrm{MPa}$ basınçla preslenen TM çelik alaşımında elde edilmiştir.

- Aşınma testlerinde en düşük ağırlık kaybı $700 \mathrm{MPa}$ presleme basıncı ile üretilen TM çelik alaşımında elde edilmiştir. En yüksek ağırlık kaybı ise $500 \mathrm{MPa}$ presleme basıncı ile üretilen TM çelik alaşımında elde edilmiştir.

- Aşınma testleri sonucunda en düşük sürtünme katsayısı $700 \mathrm{MPa}$ basınçla üretilen TM çelik alaşımında elde edilmiştir. En yüksek sürtünme katsayısı ise $500 \mathrm{MPa}$ basınçla preslenen TM çelik alaşımında elde edilmiştir.

\section{Kaynaklar}

[1] Gething, B. A., Heaney, D.F., Koss, D.A., Mueller, T.J., "The effect of nickel on the mechanical behavior of molybdenum P/M steels” Materials Science and Engineering: A, 390(1-2), 19-26, 2005.

[2] Antón, N., Delgado, J.L., Velasco, F., Torralba, J.M., "Influence of alloying element additions on tribological behaviour of sintered steels with high content in manganese-nickel” Journal of Materials Processing Technology, 143, 475-480, 2003.

[3] Zhang, Z., Sandström, R., "Fe-Mn-Si master alloy steel by powder metallurgy processing” Journal of Alloys and Compounds, 363(1-2), 199-207, 2004.

[4] Tekeli, S., Güral, A., Özyürek, D., "Microstructure and dry sliding wear properties of 3Si-2Ni and 3Si-2Mn powder metallurgy steels with different graphite content” Proceedings of the Institution of Mechanical Engineers, Part J: Journal of Engineering Tribology, 225(8), 814-820, 2011.

[5] Simchi, A., Danninger, H., "Effects of porosity on delamination wear behaviour of sintered plain iron" Powder Metallurgy, 47(1), 73-80, 2004. 
Nevşehir Bilim ve Teknoloji Dergisi (2019), 8(IMSMATEC Özel Sayı) 54-62

[6] Dhanasekaran, S., Gnanamoorthy, R., "Dry sliding friction and wear characteristics of Fe-C-Cu alloy containing molybdenum di sulphide” Materials \& Design, 28(4), 1135-1141, 2007.

[7] Gökmeşe, H., Bostan, B., “AA 2014 alaşımında presleme ve sinterlemenin gözenek morfolojisi ve mikroyapısal özelliklere etkileri” Gazi Üniversitesi Fen Bilimleri Dergisi Part C: Tasarım ve Teknoloji, 1(1), 1-8, 2013.

[8] Ekşi, A., Kurt, A.O., "Bilgisayar Kontrollü Tek Eksenli Kalıpta Preslenen Bakır ve Bronz Tozlarının Mekanik Özelliklerinin İncelenmesi” Bilim Günleri, 5-6-7 Mayıs Makine Mühendisleri Odası Bildiriler Kitabı, 544552, Denizli, 1999.

[9] Dubrujeaud, B., Vardavoulias, M., Jeandin, M., "The role of porosity in the dry sliding wear of a sintered ferrous alloy” Wear, 174(1-2), 155-161, 1994.

\section{Extended Abstract}

\section{Introduction}

Phases such as Ni-rich ferrite and martensite, commonly seen in the microstructures of nickel (Ni) and Manganese (Mn) added powder metal (TM) steels, contribute to the improvement of the mechanical properties of these steels. Ni and Mn, which are austenite stabilizers, significantly increase the hardenability as alloying elements. However, it is known that silicon ( $\mathrm{Si}$ ) is a good ferrite stabilizer and has a solid solution-enhancing effect in ferrite. Silicon is widely used in low alloy steels because of its good reinforcement and cheaper than Ni and Mo. The rich Ni-rich TM ferritic and martensite phases in the microstructure of the TM steels contribute to the mechanical properties of TM steels. The wear behavior of TM steels is influenced by properties such as microstructure, hardness, chemical composition, density and porosity. Generally, high density is desired to increase the wear resistance of TM steels. The most common method of improving wear properties is using alloying elements. In the studies, it is stated that wear resistance decreases due to surface fractures in Mn containing alloys, better abrasion resistance in Ni added alloys and abrasion occurs with plastic deformation on the surface. The porosity ratio of TM steels has a significant effect on the wear behavior. In this study, FeSiNiGr alloy produced by TM method was produced with different pressing pressure. The aim of this study is to determine the effect of different pressing pressures on microstructure, density, hardness and wear behavior under constant load.

\section{Method}

In this study, the average powder size 99\% purity iron (Fe), 99.8\% purity Nickel (Ni), 99.5\% purity silicon (Si) and $99 \%$ purity graphite were used. The powders prepared according to the chemical composition were mixed for 20 minutes using a 4:1 mixing ball:powder ratio in a turbula powder mixing device. Powders prepared by mixing process were pressed with stainless steel mold at 3 different pressing pressures (300 MPa, $500 \mathrm{MPa}$ and $700 \mathrm{MPa}$ ) and green compacts were produced. The produced green compacts were sintered at $1200{ }^{\circ} \mathrm{C}$ for 30 minutes in an atmosphere controlled oven using argon gas atmosphere at a heating rate of $5{ }^{\circ} \mathrm{C} / \mathrm{min}$ and cooled to room temperature using a cooling rate of $4{ }^{\circ} \mathrm{C} / \mathrm{min}$. It is characterized by density measurements before and after sintering and hardness measurements after sintering. The samples were prepared by standard metallographic procedures and etched with $3 \%$ nital etch for 10-15 seconds. For the microstructure studies of the etched samples, Jeol JSM 6060 brand Scanning Electron Microscope (SEM) was used. Hardness measurements of the samples were measured as HV0.2 on Shimadzu HMV tester. Wear tests standard pin-on-disc wear tester used 3 sliding distances (1000, 2000 and 3000 m) under $50 \mathrm{~N}$ load. After the wear tests, the weight loss was examined with wear rate and friction coefficients.

\section{Results and Discussion}

When the microstructures of TM steels produced at different pressing pressures are examined, it is understood that the structure consists of ferrite and perlite phases at all pressing pressures. It has been observed that at all pressing pressures, pearlitic transformations occur especially in grain boundaries with large perlite structure areas. This is thought to be due to the coating of graphite (C) powders added during powder mixing onto the surface of the iron (Fe) powders. In addition, during sintering, $\mathrm{C}$ dissolves at the grain boundaries and causes perlite transformation. It is also clearly understood that there is a reduction in the porosity ratio with increasing pressing pressure in the microstructure. When the density changes of TM steels produced at different pressing pressures were examined, the densities increased both before and after sintering with increasing pressing pressure. The pores shrinking in the structure of the samples, which become more compact with increasing compression pressure, are closed by better diffusion of the beads between each other during sintering. When the porosity ratio results are examined, it is understood that the porosity ratio 
Nevşehir Bilim ve Teknoloji Dergisi (2019), 8(IMSMATEC Özel Sayı) 54-62

decreases with increasing pressing pressure. When the hardness results of TM steels produced at different pressing pressures were examined, hardness values increased with increasing pressing pressure. It is thought that the increase of the pressing pressure and the increase in hardness result from the decrease of the porosity ratio in the structure with the effect of deformation during compression. Mechanical properties of the parts produced by powder metallurgy method are related to the porosity ratio. The porosity formed in the structure act as centers where tension is concentrated and contribute to the progression of dislocations.

When the wear results were examined, the lowest weight loss was obtained in TM steel alloy produced with $700 \mathrm{MPa}$ pressing pressure. The highest weight loss was obtained in TM steel alloy produced with $500 \mathrm{MPa}$ pressing pressure. As a result of wear tests, the lowest friction coefficient was obtained in TM steel alloy produced with 700 MPa pressure. The highest friction coefficient was obtained in TM steel alloy pressed with 500 MPa pressure. 